\title{
Distributive Justice: \\ From Steinhaus, Knaster, and Banach to Elster and Rawls - The Perspective of Sociological Game Theory
}

\author{
Tom Burns ${ }^{1}$, Ewa Roszkowska ${ }^{2}$, Nora Machado des Johansson ${ }^{3}$ \\ 1 Woods Institute for Environment and Energy, Stanford University, California and \\ Department of Sociology, University of Uppsala, Sweden, tom.burns@soc.uu.se \\ 2 Faculty of Economics and Management, University of Bialystok, Poland, \\ erosz@o2.pl \\ ${ }^{3}$ Lisbon University Institute, Centre for Research and Studies of Sociology, Lisbon, \\ Portugal, nora.machado@iscte.pt
}

\begin{abstract}
This article presents a relatively straightforward theoretical framework about distributive justice with applications. It draws on a few key concepts of Sociological Game Theory (SGT). SGT is presented briefly in section 2. Section 3 provides a spectrum of distributive cases concerning principles of equality, differentiation among recipients according to performance or contribution, status or authority, or need. Two general types of social organization of distributive judgment are distinguished and judgment procedures or algorithms are modeled in each type of social organization. Section 4 discusses briefly the larger moral landscapes of human judgment - how distribution may typically be combined with other value into consideration. The article suggests that Rawls, Elster, and Machado point in this direction. Finally, it is suggested that the SGT framework presented provides a useful point of departure to systematically link it and compare the Warsaw School of Fair Division, Rawls, and Elster, among others.

Keywords: distributive justice, fair division, sociological game theory, adjudicated distribution, self-organized distribution, distributive procedures/algorithms
\end{abstract}

\section{Introduction}

This article focuses on a particular type of universal judgment in human groups and communities, namely the one concerning distributive justice. We apply several key elements of sociological game theory (SGT) in conceptualizing a range of arrangements and procedures of distributive justice.

SGT is briefly presented in section 2 . Section 3 deals with applications of our framework to a variety of distributive justice procedures: these range from consideration of equal division in a group or community to considera- 
tion of cases of inequality due to status or authority differences, performance or contribution differences, or differences in need. The section makes a major distinction between judgments of allocation that are adjudicated and those that are self-organized or managed by members of the group or community itself. In the first case, a judge, arbitrator, political agent (they may be elected, appointed, or of traditional origin) applies a principle or procedure in the distribution process, whether it concerns equality, differentiation according to status, responsibility, performance or need. In self-organized fair distribution those participating apply division procedures or algorithms that divide fairly (although the outcomes may differ in several ways from fair division).

Our SGT based models refer to the cultural, institutional and situational context $S(t)$ at time $t$, the actors involved, their role and role relationships, and the relevant group or community values of the actors in the situation. Situational value(s) may indicate equality or difference - and the differences may range from need to status or authority level, or performance/contribution to the group. A procedure or algorithm is used to allocate in a "fair manner" in accordance with the relevant value in the situation. In adjudicated distributive procedures, the role of the legitimate authority or judge $P$ is considered in relation to the $N$ members of the group or community $N=\left\{A_{1}, A_{2}, \ldots, A_{n}\right\}$. In self-organizing distribution, one or more members of $N$ participate in the division procedure, depending on the organizing principle or algorithm applied in fair division.

Section 4, "Discussion and Summary", links, among other things, the connection of our perspective to Rawls (1971), in particular his extension of an absolute value, equality, to take into account additional value considerations such that some inequality would be acceptable if the resulting unequal distribution would be to anyone's or everyone's advantage. A further complication of distributive justice issue is found in Machado's 1998 research on the allocation of organs among candidates for transplantation. Multiple factors result in diverse and complex procedures of selection, making distributive justice one among several factors in the complex judgment. Finally, it is suggested that the article serves to link up the Warsaw school (Steinhaus, Knaster, and Banach) of "fair division" as well as others to the massive literature in the social sciences and humanities (dating back to Aristotle). It is argued that the framework outlined and the diverse models of distributive justice presented in section 3 provide a systematic and theoretically grounded basis to organize and analyze the plethora of illustrations which Elster (1992) provided in his encyclopedic work on "local justice". 


\section{The Structural Embeddedness of Social Interaction and Games}

Sociological Game Theory (SGT) has been applied in a number of areas and its relation to classical game theory has been specified and analyzed (Burns, 1990, 1994; Burns, Gomolińska, 1998, 2000, 2001; Burns, Roszkowska, 2004, 2005, 2006a). This approach stresses the institutional and cultural embeddedness of games and other forms of social interaction (Buckley et al., 1974; Granovetter, 1985). The SGT approach entails the extension and generalization of classical game theory through the systematic development of the mathematical theory of rules and rule complexes (the particular mathematics is based on contemporary developments at the interface of mathematics, logic, and computer science) (Burns,Gomolińska, 1998, 2000, 2001; Gomolińska, 1999, 2002, 2004, 2005).

(1) The approach provides a cultural and institutional basis for defining and analyzing games in their social context - game is reconceptualized as a social and often institutionalized form. The rule complex(es) of a game applied (and interpreted) in a particular social context guide and regulate the participants in their actions and interactions.

(2) SGT formulates a general theory of judgment and action on the basis of which actors either construct their actions or make choices among alternative actions in their interaction situations. They do this by making comparisons and judging similarity (or dissimilarity) between their salient norms and values, on the one hand, and the option or options considered in the game situation, on the other hand. In general, players try to determine whether or not, and to what degree a value, norm, or goal is expected to be realized or satisfied through one or another course of action (technically, they maximize "goodness of fit" (Burns, Roszkowska, 2005).

(3) Human action and interaction is explained then as a form of ruleapplication as well as rule-following action; this mechanism underlies diverse modalities such as instrumental, normative, and expressive as well as "playful" modalities for determining choices and actions. The instrumental modality corresponds to outcome-oriented rational choice theory; normative modality is characterized by a consideration of particular intrinsic qualities of the action, which relate to and satisfy given norms.

(4) SGT game theory distinguishes between open and closed games. The structure of a closed game is fixed as in classical game theory. Open games are those in which the agents have the capacity on their own initiative to restructure and to transform game components, either their individual role components, or the general "rules of the game." Game rules and 
rule complexes are seen then as human products. Rule formation and reformation are described and analyzed as a function of meta-game interaction processes.

(5) SGT re-conceptualizes the notion of "game solution", stressing first that any "solution" is from a particular standpoint or perspective, for instance, the perspective of a given player or group of players. Therefore, some of the "solutions" envisioned or proposed by players with different frameworks and interests are likely to be contradictory. Under some conditions, however, players may arrive at "common solutions" that are the basis of game equilibria. Thus, in this perspective, actors may propose multiple solutions, some of which possibly converge or diverge.

(6) SGT re-conceptualizes the concept of game equilibrium and distinguishes different types of game equilibria. Among these is a sociologically important type of equilibrium, namely normative equilibrium, which is the basis of much social order (Burns, Roszkowska, 2004, 2006a, 2007). In SGT game theory, an activity, program, outcome, condition or state of the world is in a normative equilibrium if it is judged by participants to realize or satisfy appropriate norm(s) or value(s) in the given interaction situation. Although the concept of normative equilibria may be applied to role performances and to individuals following norms, we have been particularly interested in game normative equilibria in given institutional settings. This means that the participants judge interactions and/or outcomes in terms of the degree they realize or satisfy a collective norm, normative procedure, or institutional arrangement. Examples of particular procedures that are capable of producing normative equilibria are adjudication, democratic voting, and negotiation as well as the exercise of legitimate authority.

Although the theory readily and systematically incorporates the principle that human actors have bounded factual knowledge and computational capability (Simon, 1969, p. 30), it emphasizes the high level of their social knowledge and competence: in particular, actors' extraordinary knowledge of diverse cultural forms and institutions such as family, market, government, business or work organization, among others, and the variety of different roles that they regularly perform in various domains of modern life.

1. Key components in our models are: interaction situation or context $(S(t)$ at time $t$, the actors involved (their roles and role relationships), their value(s) relevant in a particular context, the beliefs or model of the situation, and the judgment procedure(s) or algorithm(s) they use to realize their value(s).

2. Procedures are often designed (or evolve) so as to satisfy multiple norms and values. This entails structuring the process in a way that rules 
out or excludes certain actions, outcomes, and even particular evaluations and preferences that violate one or more of the multiple norms and values. For instance, in adjudication, the court process is conceptually ordered into phases so as to frame or shape the deliberations, structuring the options as well as the legal concepts and norms that apply in the different phases (Chapman, 1998a, 1998b).

Under some conditions, the proper performance or realization of the procedure is necessary and sufficient for a normative equilibrium, for instance the outcome is judged "right and proper" because the procedure is judged as fair and legitimate (Burns, De Ville, 1999).

Such societal procedures as negotiation, adjudication, and democratic vote have two-fold properties:

(1) they embody or realize a particular norm or normative complex - having a moral weight or legitimacy in themselves, for instance in terms of entailing standards of fairness, competence, and transparency;

(2) the procedure leads - or is believed to lead - to legitimate outcomes and normative equilibria, possibly fair or just outcomes, whatever these may be. ${ }^{1}$

The legitimacy accomplished by following the procedure may take precedence over the actual outcomes, which in fact might be highly unsatisfactory in themselves, to one or several or, indeed most parties. One of the following must hold:

(1) The actors assign more value to the procedure (to its inherent procedural qualities) than to any of the consequences embodied in a given or expected outcome. That is, a "negative outcome," while obviously not preferred, would be more acceptable than devaluing or rejecting the properly performed procedure. In sports, when one loses a game that is properly conducted, he usually does not publicly devalue or denigrate the game as such. The values in actors' complexes associated with "the right way" - the proper procedure - take priority over the values at stake in the outcomes. ${ }^{2}$ This is, of course, problematic for substantive outcomes that have to do with sacred matters such as religious practices or issues of abortion and desecration.

(2) The actors believe that, on the average or over the long-run, the procedure gives positive results, possibly not always best but at least a commonly agreed "not worst" result, assessed in terms of norms or values, $r_{\text {just }}$ and $r_{\text {eff }}$, that specify degrees of justice and efficiency, respectively. Results include the avoidance of escalating conflict, disruption, or anarchy. 
In general then, the normative equilibria produced through institutionalized procedures to deal with disagreement or allocation issues do not depend ostensibly on actual outcomes - or assessments of actual outcomes but on following the procedures in a right and proper way, whether a democratic vote, adjudication, or negotiation procedure. Outcomes generated by such institutional procedures are normative equilibria provided the procedures are judged to be fair and to be implemented in a right and proper way according to established social norms and laws. The outcomes of the procedure may or may not satisfy a relevant norm, for instance a principle of distributive justice adhered to by one or more involved groups, organizations, or movements. Distributive justice may concern power, positions of authority or status, wealth, or other resources - or need.

Of course, it is difficult in practice to disentangle judgments of procedural arrangements from judgments of outcome effects. Analytically, one may do so, however (Burns, DeVille, 1999; Sen, 1998). Some people - including many social scientists - might privilege one over the other. For example, a democratic process that violates no laws or community norms (rights) might, nevertheless, result in an outcome that is unsatisfactory or even disastrous for some groups such as minorities in the community. Thus, although democracy does not technically "fail," it might result in unacceptable, or even intolerable, outcome(s). Or, a process may be seen as somewhat unfair, in that it excludes certain agents or allows a single group or party to enjoy a monopolistic position, but its outcome(s) might nevertheless be judged as right and proper, according to community norms of distributive justice.

Imagine, for instance, that a central planner (or Sovereign) would know everyone's utility function as well as production function and commands each and every one in such a way as to produce a normative equilibrium satisfying a strong principle of distributive justice. The problem with this is, as Sen (1998) has pointed out, that there is a further value associated with having the freedom to make choices - to exercise human agency. In general, people may judge it improper and morally wrong to coerce a community to accept a law or political leadership, which they actually want collectively and would through a properly executed democratic procedure eventually accomplish.

The approach outlined above enables us then to identify some of the conditions under which society's procedures will generally fail to settle conflicts and achieve normative equilibria. There are limits, in other words, - that is, a certain scope - to the production of normative equilibria by such procedures. In general, actors may judge, either on indi- 
vidual or collective basis, the outcomes produced or generated as wrong, or excessively unfair, thus making normative equilibria unlikely or vulnerable. In particular,

(1) Actors disagreeing about the right and proper consequences - or about the facts in the case - may utilize procedures of rational discussion and argument, including logical and scientific argument to facilitate the resolution of the disagreement. Or, barring resolution through persuasion, they may make use of a formal democratic procedure to resolve the disagreement. These patterns - ipso facto of implementing the procedure - may lead to normative equilibria, whenever in the ideal case, the losers or minority accept the outcome (a law, regulation, or leadership) as the new "norm." It is legitimate. Such a process works reasonably well in "democratic societies" where democratic norms and values are deeply institutionalized. It works less well - or not at all - even in established democracies, if the issue at stake is a sacred one. Abortion, for instance, is an issue that deeply splits many communities. Voting on such an issue typically will not resolve it. In general, deep-felt issues such as those concerning religion, ethnicity, the sacred (for some people today, this is also the environment and animal rights) are not readily amenable to a simple voting process settling the issue. In large part, this can be explained in terms of the ordering of values. The value relevant to the issue is absolutised, so that the particular value associated with accepting and following the procedure - which transfers value to an outcome - does not measure up to the value invested in the issue itself. Therefore, such actors are not prepared to accept or comply with "the rules of the democratic game," when it comes to sacred issues such as those indicated above.

(2) While democratic, judicial, and other collective decisions may be accomplished more or less effectively, some outcomes or developments may be judged by members of the community as normatively unacceptable. This leads, of course, to pressures to reject "legitimate decisions" and to attempt to re-negotiate or to re-decide. For instance, systematic bias (perceived or believed) in the institutional arrangements leads to opposition and the refusal on the part of some to abide by democratic decisions (instead, they engage in "civil disobedience" or "coercive action" such as terrorism). In particular, outcomes may be judged as consistently unrepresentative (of their own or others' views), even though an apparently right and proper democratic procedure (such as majority rule) had been followed in determining them. Consequently, they reject the outcome(s), judging themselves to be a discriminated minority in that their values are not "represented in the outcomes." 3 The validity of the 
claim is not under consideration here. It is rather the readiness to reject outcomes of a particular "legitimate procedure" for settling or resolving a conflict.

(3) There may be no institutionalized procedure readily available or acceptable to negotiate or collectively decide an issue on which there is fundamental disagreement. For example, a constitution is judged by a substantial proportion of a community to be ineffective or no longer legitimate (because, for instance, it discriminates against groups such as minorities). Reform is demanded, but even on the level of institutional reform there is no readily available or efficient procedure to negotiate and collectively decide such constitutional matters. In general, institutions of governance may be judged as inappropriate or illegitimate, yet possibilities of effective reform may be blocked or heavily constrained. Consequently, the societal capacity to produce normative equilibria is greatly reduced, setting the stage for societal crisis.

In sum, normatively grounded outcome equilibria may be obtainable through the utilization of societal procedures that settle (not necessarily resolving) conflicting views, interpretations (of a law or contract), values or evaluations, proposals, etc. Institutionalized procedures such as voting, adjudication, negotiation with the participation of opposing agents not only legitimize resulting outcomes but give them a normative force. An outcome is collectively defined or understood as right and proper by virtue of having resulted from application of the right and proper procedure. ${ }^{4}$ In other words, the procedure itself generates outcomes that derive normative force from application of the procedure itself. This is a type of institutional alchemy. In societies with such social processes, participants (and other societal agents) are likely to sanction negatively those who refuse to accept the outcomes of a right and proper procedure, for the refusal is tantamount to criticizing or denigrating the procedure. However, as suggested above, there are limits to such legitimation of outcomes (Burns et al., 1998; Burns, Gomolińska, 2000, Burns et al., 2001). This is obvious in the case of substantive matters of a sacred character to one or more participants, for instance, issues such as abortion, physician assisted suicide, violation or desecration of sacred objects or places, etc., but also issues that touch on deep cleavages between groups, classes, and communities.

For the purposes of this paper, we distinguish between adjudicated procedures (administration, court, leadership agent) as opposed to a group self-managed process. In both arrangements, principles are relevant and applied, for instance, a principle of equality. This relates to earlier papers 
where we identified societal procedures to resolve conflicts and made collective choices, for instance, choice of an allocation procedure and its purpose.

Two key characterizations of groups are egalitarian, on the one hand, and differentiated (typically hierarchical), on the other. ${ }^{5}$ For instance, a group may have been established and functions on egalitarian principles, so allocation of an available good (or bad) would be done according to a principle of equality (this may take different forms). ${ }^{6}$

In a group with prominent status differences, which are considered highly important and relevant for the distribution of a resource (such as the results of a business or professional venture, they would distribute unevenly. Some procedures or rules may be recognized by the group to accomplish such unequal distribution. The levels differentiated may be $2,3, \ldots, k$.

As mentioned above, the differentiation can be based on status or authority in the community or group. Performance for or contribution to the group may also be a basis for such differentiation. Those performing at the highest level or contributing the most to the group or its output would receive the most, and those performing or contributing less, would receive less, and so on. Finally, differentiation may be based on need, the needier receiving more than those needing less.

In general, one may distinguish distributions that are intended to accomplish or reflect equality and those that accomplish or reflect differentiation. And, as suggested above, the bases of differentiation may vary from group status, performance or contribution to the group, to neediness. ${ }^{7}$ But groups may choose to ignore differences in performance or contribution or even need and allocate to every member the same good, or amount of a good, regardless.

In the case of an adjudication arrangement, the judge $\mathbf{J}$ may be appointed, or elected by members of the group, or by a larger community (in the latter case, with authorization presumably to deal with the particular group in question). Burns and Flam (1987) refer to cases of allocation in different areas (housing, health care, subsidies) by government agents to subgroups of citizens. Some firms and organizations conduct such distribution among its employees, and many voluntary organizations provide its members with access to training and other educational opportunities, health care, possibly pensions.

In our cases, discussed below, the group or its leadership adheres to a procedure or algorithm for allocation. But the arrangement may be for a judge/leader to allocate arbitrarily, or to do it on the basis of a lottery. ${ }^{8}$ If the allocation is arbitrary, the leader or judge typically requires 
a great deal of authority or power to overcome disappointment and envy among the members. Often an arbitrary judge would try to conceal the amounts of allocation to different members (using secrecy or a "veil of ignorance").

\section{Applications to Distributive Justice Procedures ${ }^{9}$}

Judgment is a core concept in SGT (Burns, Gomolińska, 2000, 2002; Burns et al, 2001; Burns, Roszkowska, 2004; Burns et al, 2005). Several types of judgments can be distinguished, for instance, value judgments, factual judgments, action judgments, among others. For our purposes here, we concentrate on judgments and decisions about action, in particular the fair allocation of scarce resources. ${ }^{10}$

We are concerned here about a particular type of judgment, namely judging fair distribution, or as it is sometimes referred to, distributive justice. $^{11}$

As indicated earlier, our models refer to the cultural, institutional and situational context $S(t)$ at time $t$. Also, the actors involved, their role and role relationships are indicated. In adjudicated procedures, the role of the legitimate authority or judge $P$ is considered in relation to the $N$ members of the group or community $N=\left\{A_{1}, A_{2} \ldots, A_{n}\right\}$, the situational beliefs or model and the values of the actors in the situation. Situational value may indicate equality or difference - and the differences may range from need to level of credential (and other measures of status), or performance/contribution to the group. Finally, a procedure or algorithm is used to allocate in accordance with the relevant value in the situation. ${ }^{12}$

\section{PART A: Adjudicated}

Several models can be proposed to describe how recipients in the Context combine information about inputs, type of goods, purposes, relationships between as well norms to produce division algorithm.

We envision a legitimate authority $P$ in a given Context, who activates and applies an established distributive procedure or function. Under some conditions, it can be "self-organized" as in the fair division cases we consider below. Given an authority $P$ with a right and knowledge to apply an allocation or distribution procedure concerning a good (or goods) $G$ to be divided among a group or population $N$ of actors, $N=\left\{A_{1}, A_{2} \ldots, A_{n}\right\}$. The good $G$ may be divisible into $N$ parts, not necessarily equal parts; or di- 
visible into $k$ parts; or non-divisible. The basis of the allocation is a principle (an allocation rule) for example, to allocate according to equal shares, or status, according to "merit" (performance or credentials), according to need, according to property rights, etc.

Case 1: Equal division by an authority $P$ is more or less straight forward if $G$ is fully divisible. The recipients, the population $N$, is identified, and the good $G$ is divided into $N$ equal parts. Each recipient receives $1 / N$ part of good $G$.

Division may take into account status differences (or in merit differences whether in terms of performance or credentials). Two cases are of interest:

Case 2A: The $N$ actors are all differentiated with respect to some criterion (for instance general social status):

$$
A_{1} \geq A_{2} \geq \ldots \geq A_{n}
$$

The total available to be distributed is good $G$, and it is assumed to be fully divisible. Let us assume that $X_{0}$ is the part of good $G$ given to each and every member $k$ of the group, a type of base amount, where $n X_{0}<G$. The difference $G-n X_{0}$ is the amount available to be distributed (since each and every member will receive the base amount $X_{0}$ ).

Let us assume that the amount is distributed incrementally increased by an amount $p$ given to actor $A_{1}$. That's means that actor $A_{2}$ receiving $2 p, \ldots$, $A_{i}$ receiving $i p$ and $A_{n}$ receiving $n p(i=1,2, \ldots, n)$. Then we have

$$
G-n X_{0}=\frac{p(1+n) n}{2}
$$

and consequently

$$
p=\frac{2\left(G-n X_{0}\right)}{(1+n) n}
$$

Hence the actor $A_{i}$ received the part $X_{i}$ of good $G$, where

$$
X_{i}=X_{0}+i \frac{2\left(G-n X_{0}\right)}{(1+n) n} \quad(i=1,2, \ldots, n)
$$

Case 2B: The total available to be distributed is good $G$ and it is assumed that it is divisible into $k$ parts with $G / k$ the value of each part of $\operatorname{good} G$.

In the first step of the procedure each recipient obtains pieces $y_{i}$ $\left(y_{i} \in N\right)$ of $\operatorname{good} G$ where 
Tom Burns, Ewa Roszkowska, Nora Machado des Johansson

$$
y_{1} \frac{1}{k}=p_{i} / \sum_{i=1}^{n} p_{i}<\left(y_{i}+1\right) \frac{1}{k}
$$

In the case where $\sum_{i=1}^{n} y_{i}<k$, the rest $k-\sum_{i=1}^{n} y_{i}$ pieces of good $G$ can be divided by the $n$ recipients using other procedures.

Good $G$ might not be divisible or, in the case of divisibility, may any good less than $G$ would be insufficient or not useful. In this case, a lottery may be used for a "fair procedure", where each member, $A_{i}$, has an equal chance at obtaining the good $G$.

Less extreme cases would be that $G$ would be sufficient for $e$ shares, $e<N$. A procedure would be used to select $e$ persons from among the $N$, and then each of the $e$ persons would receive a share $G / e$. Or, there could be different categories of $e$ with a "first prize", "second prize" and "third" - with the actors in the different categories adding up to $e$, etc.

Case 3. Instead of all the actors being distinguished as in case 1 above, they could be divided into, for example, $k$ categories, for instance 3 categories: high status, medium status, low status (or high need, low need, no need). The $N$ persons might be divided into $c$ persons in the top category, $b$ in the second and $a$ in the third. And a rule specifies that a certain proportion is applied to the three levels. $1: 3: 5$ (in the case of need, the no need category would receive no payment, so that the rule might be the proportion $1: 3$. Then the good $G$ would be divided accordingly. Or in a simpler case, the distinction could be between those in need, $k$ actors, and those not in need $n-k$. If the division is equal, then $G=k X$ and $X=G / k$.

Case 4. We assume here that with the problem of division of goods, authority has to take into account not a single norm but a set of norms (criteria) $X=\left\{X_{1}, X_{2}, \ldots, X_{m}\right\}$. For $m$ norms, we might have weight vector $w=\left[w_{1}, w_{2}, \ldots, w_{m}\right]$ which satisfies

$$
w_{1}+w_{2}+\ldots+w_{m}=1, \quad w_{j} \geq 0 \text { for } i=1,2, \ldots, m
$$

where $w_{j}$ represents the weight of norms $X_{j}$.

We assume that all division parts with respect to all norms have been estimated separately. Every division with respect to the $i$-th norm $X_{i}$ is represented by a vector $\left[x_{1 i}, \ldots, x_{n i}\right]$, where $x_{1 i}+\ldots+x_{n i}=1(i=1,2, \ldots, m)$.

A multi-criteria division problem with set of $n$ recipients $A=$ $\left\{A_{1}, A_{2}, \ldots, A_{m}\right\}$ and a set of $n$ norms $X=\left\{X_{1}, X_{2}, \ldots, X_{m}\right\}$ can be expressed by allocation (judgment or decision) matrix $D=\left(x_{i j}\right)_{n \times m}$ and the weight vector $w=\left[w_{1}, w_{2}, \ldots, w_{m}\right]$. The multi-value division problem can be represented as (Hwang, Yoon 1981): 
Distributive Justice: From Steinhaus, Knaster, and Banach...

$$
D=\begin{array}{cccc}
X_{1} & X_{2} & \cdots & X_{n} \\
A_{1} \\
A_{2} \\
\vdots \\
A_{m}
\end{array}\left[\begin{array}{cccc}
x_{11} & x_{12} & \cdots & x_{1 n} \\
x_{21} & x_{22} & \cdots & x_{2 n} \\
\vdots & \vdots & \ddots & \vdots \\
x_{m 1} & x_{m 2} & \cdots & x_{m n}
\end{array}\right]
$$

where $x_{i j}$ is the part of good $G$ for the $i$-th recipient with respect to the $j$-the norms $(i=1,2, \ldots, m ; j=1,2, \ldots, n), x_{i j} \in \mathfrak{R}$.

In the final step, the SAW score for each recipient is calculated as follows

$$
S_{i}=\sum_{j=1}^{m} x_{i j} w_{j}
$$

where $S_{i}$ is the score for the $i$-th recipient, and $x_{i j}$ is the score for the $i$ th recipient with respect to the $j$-th norm and $w_{j}$ is the weight of criteria $j$ as before. Next the final scores are normalized. The part of good $G$ for the $i$-th recipient is the following:

$$
S_{i} / \sum_{j=1}^{n} S_{j} .
$$

Case 5. The divisions might be less strictly orderly, for instance, there is no rule of proportions, but the authority decides an amount for each category of actor.

\section{PART B: Self-organizing fair division procedures in groups}

In this part we discuss usability of the techniques of fair division in the construction of legitimate normative social procedure. The fair division procedure can be applicable in a special class of social collective decision concerning the problem of dividing some object fairly. In general,the problem of fair division of goods is the subject of extensive literature in the social sciences, law, economics, game theory and other. Usually, this object is referred to as cake, but in general it could be desirable, undesirable or a mixture of desirable and undesirable goods. The good may be infinitely divisible (as we usually regard real cake, money) or only divisible into discrete pieces (such as house, car, furniture).

The theory of fair division among a group of individuals was initiated in the 1940s by three Polish mathematicians: Hugo Steinhaus, Bronisław Knaster and Stefan Banach. ${ }^{13}$

Their famous "cake cutting" problem is described in the following way:

There are $n$ players wishing to divide between themselves a single "cake". ${ }^{14}$ The different players may value differently the various sections of the cake, e.g. one player may prefer the marzipan, another the cherries, 
and the third player may be indifferent between the two. The goal is to obtain a "fair" division of the cake amongst the players.

Description of the problem. Let $N=\{1, \ldots, n\}$ be a set of agents (or players, or individuals) who need to share several goods (or resources, items, objects). An allocation $A$ is a mapping of agents to bundles of goods. Most criteria will not be specific to allocation problems, so we also speak of agreements (or outcomes, solutions, alternatives, states). A group of agents each have individual preferences over a collective agreement or the allocation of goods to be found, division preferences are often assumed to be utility functions and fair allocations problems of goods come with some internal social structure. The problem is notion and understanding of "fairness" allocation as well its relationships with economic "efficiency". The problem is: how to find the legitimate procedure which satisfies fairness conditions? The theory of fair division provides explicit criteria for various different types of fairness.

Its aim is to provide procedures to achieve a fair division, e.i satisfy a norm or prove its impossibility, and study the properties of such divisions both in theory and in real life.

A Fair Division Procedure (algorithm) describes the way of dividing one or several goods amongst two or more agents in a way that satisfies suitable properties. There are several possible definitions to what constitutes a "fair" division, where proportionality, envy freeness and equitability are the major fairness criteria being considered.

We will say a fair-division method is:

(1) proportional or simple if and only if each of $n$ participants gets what he or she considers to be at least $1 / n$ of the total value of the object or objects divided. A proportional fair division guarantees each player gets his/her fair share, so at least $1 / n$ according to his/her own valuation.

(2) envy-free if and only if no participant experiences envy. An envyfree division guarantees that no-one will want somebody else's share more than their own. No player will envy (any of) the other(s).

(3) envy with respect to participant experiences if and only if he or she would prefer to trade his or her portion of the division with some other participant.

(4) Pareto-optimal if and only if there are no possible exchanges or different allocations that would benefit at least one participant that does not also make at least one other participant worse off. An efficient or Pareto optimal division ensures no other allocation would make someone better off without making someone else worse off. The term efficiency comes from the economics idea of the efficient market. A division where one player gets 
everything is optimal by this definition so on its own this does not guarantee even a fair share.

(5) equitable if and only if each participant believes he or she has received the same fraction of the total value of the object or objects divided. An equitable division is one where the proportion of the cake a player receives by their own valuation is the same for every player. This is a difficult aim as players need not be truthful if asked their valuation.

We will say a procedure of fair-division is fair if procedure satisfies one of the preceding criteria of fairness (either proportionality, envy-freeness, Pareto-optimality, equitability or other), so every participant considers the allocation fair in that sense. The fair criteria can conflict with each other but often they can be combined. Any envy-free division is also proportional, but there are proportional divisions that are not envy-free. Brams has shown that efficient and envy-free divisions may be incompatible because a unique envy-free division may be inefficient, there may be no envy-free division at all or existence of even a unique efficient and envy-free division may not be chosen by the players for other reasons (Brams et al, 2000).

The aim of social mechanics is the analysis of organized activities which must start from the recognition of the criteria associated to each action, determining which can be accepted by players involved in decision making. After giving a precise specification of the properties to be satisfied by a fair division procedure we proceed to the description of a constructive procedure. Such procedure gives the instruction how to make partition, the number of (non-intersecting) cuts allowed for partitioning the good and what certain properties are satisfied by the allocation. Procedures can be distinguished on the basis of certain technical aspects. One distinction is between discrete and moving-knife procedures. In discrete procedures, the players' moves are in a sequence of steps, whereas in moving-knife procedures, there is a continuous evaluation of pieces of cakes by the single players. Another further essential distinction is based on the number of (non-intersecting) cuts allowed for partitioning the good. Algorithms satisfying desirable fair properties, or showing the limits of doing so, can be referred to as institutional legitimate procedures. We can analyze step-by-step rules or algorithms to implement the fair division of goods in normative aspects and study their distributional consequences. By making precise properties that one wishes fair-division procedure to satisfy and clarifying relationships among these properties we can analyze implementation of those procedure in social context to resolve conflict.

In such concept a Fair Division Procedure is a complex of rules that, when properly applied, produces a fair division of the objects 
to be divided. It is a list of actions to be performed by the players in terms of the visible data and their valuations. Usually we expect any fair division procedure is decisive, so if the rules are followed, a fair division is assured, internal to the players, so no outside intervention is required to obtain a fair division, legitimize (players agree for it). Moreover players have no knowledge of each others' value systems, they are rational, make logical decision. The players have to agree on criteria for a fair division, select a valid procedure and follow its rules. Beyond fairness, additional desirable properties of procedure include simplicity, self-implementation, minimal number of cuts, and applicability to any number of participants in real-life conflicts.

The main elements of a Fair Division Problem are the following:

(1) A set of $N$ players (agents): $A_{1}, A_{2}, \ldots, A_{n}$

(2) A set of goods, $S$ to be divided.

The problem is to divide the set $S$ into $N$ shares $\left(s_{1}, s_{2}, \ldots, s_{n}\right)$ so that each player gets a "fair share" of S.

In general, a fair share is any share that, in the opinion of the player receiving it, has a value that is at least $1 / N$ of the total value of the set of goods, $S$ ( $N$ is the number of players.) Observe that share value is subjective and that each player may even have a different notion of how much the set to be divided is worth. The Fair Division Procedure does not guarantee each player a fair share but does guarantee that no other players or bad luck can deny a player his/her fair share. A player may misplay the game and, by so doing, receive less than his/her fair share. Many intuitive algorithms guaranteeing "fairness" have been devised (Brams, Taylor, 1996). Here we presented some of them.

\section{Cut-and-Choose (The Divider-Chooser) Procedure}

It is the classical approach for dividing a cake between two players: The payer 1 cuts the cake in two pieces which she/he considers to be of equal value, next the player 2 chooses one of the pieces which she/he prefers. ${ }^{15}$ In general the steps of "cut and choose" algorithm are the following:

1) A randomly chosen player (the Divider) divides the set $S$ into 2 pieces.

2) The other player (the Chooser) selects the piece.

The "Cut and Choose Procedure" is proportional, envy-free but it is not Pareto optimal. ${ }^{16}$

\section{The Steinhaus Procedure}

This procedure for three players was proposed by Steinhaus around 1943 (Brams, Taylor, 1995).

1) Player 1 (Divider) divides the set $S$ into 3 pieces which she/he values equally. 
2) Player 2 "passes" if he/she thinks at least two of the pieces are $1 / 3$ or labels two of them as "bad". If player 2 passed, then players $3,2,1$ each choose a piece (in that order) and we are done.

3 ) If player 2 did not pass, then player 3 can also choose between passing and labelling. If player 3 passed, then players $2,3,1$ each choose a piece (in that order).

4) If neither player 2 or player 3 passed, then player 1 has to take (one of) the piece(s) labelled as "bad" by both 2 and 3 . The rest is reassembled and 2 and 3 use "Cut-and-Choose Procedure".

The Steinhaus procedure guarantees a proportional division of the object (under the standard assumption that players are risk-averse, so they want to maximize their payoff in the worst case), is not envy-free, is a discrete procedure that does not require a referee, requires at most 3 cuts, the resulting pieces do not have to be contiguous.

\section{Lone Divider Procedure}

The "Lone Divider Procedure" is a generalization of the "Cut and Choose Procedure" for ( $N$ player). One participant is randomly designated the divider, and the rest of the participants are designated as choosers. The procedure proceeds as follows:

1) A randomly chosen player (the Divider) divides the set $S$ into $N$ pieces $\left(s_{1}, s_{2}, \ldots, s_{n}\right)$.

2) Each of the choosers will separately list which pieces they consider to be a fair share (acceptable pieces). This is called their declaration, or bid. The lists are examined by the referee. There are two possibilities:

a. If it is possible to give Choosers a piece they declared as acceptable then do so, and the Divider gets the remaining piece.

b. If two or more Choosers both want the same piece and none other, then give a non-contested piece to the Divider. The rest of the pieces are combined and the entire procedure is repeated with the remaining parties. If there are only two players left, they can use "Divider-Chooser Procedure".

The "Lone Divider Procedure" is proportional but not envy-free.

\section{The Banach-Knaster Last-Diminisher Procedure}

The Last Diminisher method is another approach to division among 3 or more parties. ${ }^{17}$ In this method, the players are randomly assigned an order (perhaps by pulling names out of a hat).

The procedure then proceeds as follows:

1) The first player cuts a slice they value as a fair share. 
2) The second player examines the piece.

a. If they think it is worth less than a fair share, they then pass on the piece unchanged.

b. If they think the piece is worth more than a fair share, they trim off the excess and lay claim to the piece. The trimmings are added back into the to-be-divided pile.

3) Each remaining person, in turn, can either pass or trim the piece.

4) After the last person has made their decision, the last person to trim the slice receives it. If no one has modified the slice, then the player who cut it (the "last diminisher") is obliged to take it.

5) Whoever receives the piece leaves with their piece and the process repeats with the remaining $n-1$ players. Continue until only 2 people remain; they can divide what is left with the "Divider-Chooser" Procedure.

This procedure is proportional, not envy-free with bounded number of cuts.

\section{Moving Knife Procedure}

Dubins and Spanier (1961) proposed an alternative proportional procedure for arbitrary $n$. In this method, applied to a "cake",

1) A judge or arbitrator (elected or appointed) starts moving a knife from left to right across a "cake".

2) As soon as any player feels the piece to the left of the knife is worth a fair share, they shout "STOP." The referee then cuts the "cake" at the current knife position and the player who called stop gets the piece to the left of the knife.

3) This procedure continues until there is only one player left. The player left gets the remaining "cake".

This procedure produces contiguous slices, uses a minimal number of cuts, it is continuous (however discretisation is possible by asking players to mark the cake where they would call "stop") and requires the help of a referee. This is also not envy-free because the last chooser is best off. She or he is the only one who can get more than $1 / n$.

\section{Sealed Bids Method}

The Sealed Bids method provides a method for discrete fair division, allowing for the division of items that cannot be split into smaller pieces, like a house or a car. Because of this, the method requires that all players have a large amount of cash at their disposal. The method begins by compiling a list of items to be divided. Then: 
1) Each player involved lists, in secret, a dollar amount they value each item to be worth. This is their sealed bid.

2) A judge or arbitrator (elected or appointed) collects the bids. For each party, they total the value of all the items, and divide it by the number of parties. This defines their fair share.

3) Each item is awarded to the highest bidder.

4) For each player, the value of all items received is totaled. If the value is more than that party's fair share, they pay the difference into a holding pile. If the value is less than that player's fair share, they receive the difference from the holding pile. This ends the initial allocation.

5) In most cases, there will be a surplus, or leftover money, in the holding pile. The surplus is divided evenly between all the players. This produces the final allocation.

The Table 1 contains some comparisons of properties of described fair division procedures.

Table 1

Comparison of properties some fair division procedures

\begin{tabular}{|l|l|}
\hline \multicolumn{1}{|c|}{ Type of procedure } & \multicolumn{1}{c|}{ Properties (norms) } \\
\hline Cut-and-Choose & Proportional, envy-free, not Pareto optimal \\
\hline The Steinhaus Procedure & $\begin{array}{l}\text { Proportional, not envy-free, discrete, does not require } \\
\text { a referee, requires at most } 3 \text { cuts }\end{array}$ \\
\hline Lone Divider Procedure & Proportional, not envy-free \\
\hline Last-Diminisher Procedure & Proportional, not envy-free with bounded number of cuts \\
\hline Moving Knife Procedure & $\begin{array}{l}\text { Contiguous slices, uses a minimal number of cuts, } \\
\text { it is continuous however discretisation is possible, } \\
\text { requires the help of a referee, not envy-free }\end{array}$ \\
\hline Sealed Bids Method & Discrete division, requires the help of a referee \\
\hline
\end{tabular}

Source: own study.

All of these historically important cases focused on equal division. However, self-organizing arrangements can also be designed for cases of differentiation. Consideration of these cases would take us beyond the scope of this article. However, the procedures we formulated to replace Pareto optimization are a useful point of departure. 
Tom Burns, Ewa Roszkowska, Nora Machado des Johansson

\section{Summary}

What is of particular interest is when more than one principle is applied.

(1) Rawls' (1971) general point of departure was the principle of equality but in his conception of an effective justice, he included an effectiveness criterion. Some degree of inequality would be acceptable if it meant a gain for all: "All social values - liberty and opportunity, income and wealth are to be distributed equally unless an unequal distribution of any, or all, of these values is to everyone's advantage."

(2) For instance, Machado (1998) in her research on organ transplantation in Europe, and in particular on the selection of recipients for organs, describes complex rule regimes applied in organ allocation. In general, once on a waiting list, a patient's selection will depend on the particular criteria specified by the rules and procedures of selection of organ recipients. There is no single, universal model - which is perhaps surprising in an area of high technology and advanced scientific medicine (Machado 1998 p. 75). In the USA from the 1990s, the nationally organized organ allocation system (UNOS) operates with the following factors (Machado 1998 p. 218-219): (1) waiting time; (2) quality of antigen mismatch; (3) panel reactive antibody; (4) medical urgency; (5) paediatric status; and (6) donor status. Points are awarded for each factor: for instance, for each full year of waiting time, a patient accrues 1 point. There are separate calculations for each geographic level (local, regional and national) of kidney allocations. The local points calculation includes only patients on the local Patient Waiting List; the regional calculation includes only patients on the region list without the local patients. The national points calculation includes all patients on the national list excluding all patients listed on the Host organ procurement organization's local and regional lists. Similarly, there are point assignments for the number of antigen mismatches and for medical urgency; for paediatric status a kidney transplant candidate who is less than 11 years old is assigned four additional points for kidney allocations, and a candidate between 11 and 18 receives three additional points for kidney allocations. (These points continue until the person reaches 18 years of age). Other systems have similar but not identical arrangements, for instance giving an advantage to patients from hospitals which have provided more than their fair share of organs (Machado, 1998). Some allocation systems are operated purely on the basis of an algorithm; others allow transplant teams to deliberate and make their own judgments; in some cases this can be very time-consuming but the participants feel that they know their cases better and are able to make better selections. Or- 
gan transplantation demonstrates the multiple factors: local justice, issues of likely effectiveness, exchange relations and obligations with other hospitals, etc.

(3) In general, this is suggesting a broader moral landscape. Typically, there are multiple justice principles applicable in a given setting, and attempts are made to combine them. Elster (1992) in his encompassing study with many cases, including complex cases such as allocation organs to recipients for organ transplantations illustrates the diversity of values and procedures in distributive justice. He also emphasizes that a "fair division" need not be an equal division (Elster 2006).

In everyday social life there are multiple values and allocation procedures realizing or leading to unequal rather than equal division. He writes: Allocative principles of the type "To each according to his X," where $\mathrm{X}$ could be need, effort, efficiency (ability to convert the scarce good into welfare), temporal priority, or one of many other criteria (Elster, 1992), may in a given situation be perceived as fairer than an equal split. Often, however, more than one principle may apply. One worker may say, "I should earn more because I have children," whereas another might say, "I should get more because I worked harder." In such a case, equal division may be chosen as a focal point compromise between competing fairnessbased claims (Schelling, 1960), rather than because of any intrinsic fairness property of equal division. Often, however, it may be hard to tell whether equal division is chosen on grounds of fairness or because of its focal-point properties.

(4) This article did not have the ambition to provide a full-blown theory of distributive justice. But we have built on the earlier foundations of sociological game theory - with its stress on normative and institutional factors. It also provides the components of the diverse models of fair distribution presented here. The work of the Warsaw School and others can be extended to differentiated allocation rather than equal division, as indicated above. The fair-division methods needed a theory which our approach provides - our work here is a start in integrating these major innovators into the vast literature in the social sciences and humanities. It also provides a systematic and theoretically grounded way to organize the plethora of illustrations which Elster (1992) provides in his encyclopedic work. Finally, Rawls who has inspired so many to reflect on issues of justice and normative approaches pointed the way to broadening the moral landscape. Our case 4 (with the application of multiple norms) is one step toward taking into account and analyzing normatively complex judgment situations. 
Tom Burns, Ewa Roszkowska, Nora Machado des Johansson

APENDIX: DISTRIBUTIVE JUSTICE REGIME MODEL

\section{CONTEXT: T}

2. GROUP OR COMMUNITY $\mathrm{C} \leftrightarrow$ RULE REGIME $(\mathrm{RR})^{18}$

- Category system in the rule regime differentiates types of situation, $S_{1}, S_{2}, \ldots, S_{i}$

- Another category system is applied to the relevant population/ group/organization $N$. In the case of differentiation of the population, there are rules about how many categories of the population $N$ are to be distinguished in situation $S_{i}$.

- Values VAL (the rules of) describe what is to be distributed, a valuable or good (or a "bad") $G_{i}$ in situation $S_{i}$ and what is the "purpose" or the "justice principle" to be applied and realized. For instance, "equality" or "differential reimbursement" (these may relate to "performance" or "contribution" or "status/authority" or "need", etc.) The value complex may also specify standards.

- Rules and algorithms J(ALG) about how to realize/achieve the purpose or principles VAL applying in situation $S_{i}$ to population or subpopulation $N_{i}$ : (a) And the differences (amounts or measures) or proportions that are to be allocated/applied to the different categories. Even in the case of a lottery procedures to be applied to a population differentiated by weights, for instance, the likelihood of being selected; (b) Further rules, for instance about exceptions.

- There are associated discourses justifying the values/principles as well as algorithms applying in Situation $S_{i}$ (see below concerning response judgments and discourses).

\section{RESPONSE OF RECIPIENTS TO THEIR ALLOCATION.}

- These may concern allocation or relative allocation, or even the overall amount - that is, a judgment if the value and norm and algorithm are sufficiently appropriate or not. Or, if they have been interpreted correctly or activated/implemented properly.

- Ultimately, there is a politics of distributive justice. 


\section{Schema: DISTRIBUTIVE JUSTICE REGIME MODEL}

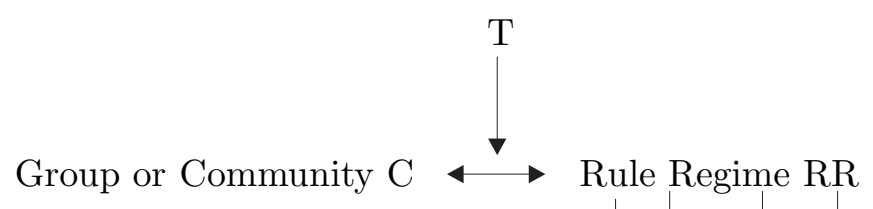

Rules for categorization of situations (subcomplex of RR): $S_{1}, S_{2}, \ldots, S_{j}$

Definition of the given Situation $S_{i}$ involving $N, G, V A L, J(A L G)$

Rules for categorization of the population $N$ (into sub-groups) in $S_{i}$ (subcomplex of RR)

Appropriate subgroups: $K_{1}+K_{2}+\ldots+K_{l}=N$

Appropriate value or principle $V A L\left(S_{i}\right)$ defining the valuable or good $G$ and the correct distribution or allocation

Selection or construction of a judgment algorithm $J(A L G)$ that realizes the appropriate $V A L\left(S_{i}\right)$, for instance "equality" or "differentiation" on the particular relevant dimensions

Application of the appropriate distributive judgment algorithm $J(A L G)$ for allocating $G .{ }^{19}$

Allocation of $G$ in the Group or Community $C$ in $S_{i}$ according to appropriate values and algorithms 


\title{
Acknowledgements
}

\author{
This work was partially supported by the grant from Polish National \\ Science Center DEC 2011/03/B/HS4/03857.
}

\section{N O T E S}

1 Some procedures make more sense than others: "Flipping a coin" is fair in a certain sense but inefficient in outcome in many cases, for instance, in the selection of recipients for organ transplantation. It ignores the differential likelihood among potential organ recipients of rejection of organs; or it ignores differences among potential recipients in the degree of precariousness of their health (Machado, 1998). Or, it disregards the length of time people may have been waiting for an organ transplant. Ranking potential recipients in terms of waiting time is certainly fair in a certain sense, but inefficient in that mismatches between organ and recipient are more likely, since it ignores the likelihood of rejection among potential recipients (and could, therefore, make for wastage of organs). Assigning points or classifying according to degree of match and then selecting according to waiting time is one way of trying to combine efficiency with a common notion of fairness.

2 Note that this is the counterpart to rational instrumentality for which value derives from the outcomes and nothing - except value associated with its outcomes - derives from the action or means itself (its qualities, expressiveness, etc.) which bring about the outcome.

3 The processes and outcomes may be complex, ambiguous, varying. What is veiled is that group formation, alliance formation, variation in issues etc. may or may not lead to acceptable, tolerable outcomes.

${ }^{4}$ Of course, the informational conditions and the context itself may contribute to an effective procedure. Rawls' "veil of ignorance" is a social condition which facilitates arriving at normative agreements. Also, there may be roles such as judges and mediators which carry normative weight in conducting procedures so that they are likely to lead to normative equilibria. This raises questions about the design of such procedures, a matter which cannot be addressed here.

${ }^{5}$ Individuals in a particular group context may operate from the beginning with an assumption that they are equal to all others in the situation - or they may operate with an assumption that they are either superior or inferior to others in a hierarchical group.

6 One may distinguish absolute equality, for instance equal rights to vote, or each member receiving an absolute equal amount. But some allocations are designed to accomplish relative equality, for each member receives the same percentage increase (or decrease) over their current salary. But the amounts differ according to their different wage baselines. This is also the case of the EU Baltic fisheries regime. Fish quotas of acceptable catches for each fisherman are based on historical catches. So, equality in a certain sense is maintained, but the quotas are very unequal - and a constant source of tension and disagreement - both about the "facts" of the case and the values and allocation procedures applied.

${ }^{7}$ Markets are often viewed as providing equality, but this is a misunderstanding. Participants are unequal by virtue of their differing market buying power or capacity.

${ }^{8}$ Lotteries are particularly used in a situation of equality for goods that cannot be divided or can be divided with great loss or resulting lack of usefulness. While a lottery appears superficial to fit an equal membership, in fact, it can be set up to give a greater chance to some members than other members, where the unequal chances correspond to the unequal statuses (or the unequal chances are designed to reduce differences in status). 


\section{Distributive Justice: From Steinhaus, Knaster, and Banach...}

9 We are not considering a general theory of justice encompassing an entire society or community of societies. There are many other justice issues.

10 Note that action judgment is a more general concept than that of "decision". Decision is a special type of judgment, choice among objects or alternatives, or determination or selection of action.

11 The concept of distributive justice goes back to Aristotle who was concerned, as many social scientists, with the question of who should get what, who gets what. This is much narrower than justice in general in society, where, for instance, some issues of justice are concerned with the judgment of agents in their behavior and social interactions (in particular, punishing an agent for an offense or rewarding one for an excellent performance). Cook (1989) emphasizes the universality of distributive justice questions and processes: "All social systems evolve mechanisms for distributing value resources and for allocating rights, responsibilities, costs and burdens. Theories of distributive justice specify the conditions under which particular distributions are perceived (should be perceived?) to be just or fair (Cook 1989, p. 205). Johnson another sociologist (2000, p. 164) suggests: "In the simplest sense, justice is a concept referring to fairness and the process of people getting what they deserve in a certain socio-cultural context with particular values and justice procedures. In a legal sense, for example, justice consisting of treating everyone (equally) according to the law, of guaranteeing civil rights and following prescribed procedures in a consistent and evenhanded way" (Johnson 2000, p. 164).

12 Often, there is a politics (a meta-process) about the value and procedure used in the situation or the actual outcome accomplished by the procedure.

13 They used to meet in the Scottish Café in Lvov (then in Poland). Brams and Taylor (1996) give a historical introduction of fair division and provide a detailed discussion of many procedures.

14 The "cake" stands as a metaphor for a single heterogeneous good, and the goal is to divide the cake between some players.

15 The problem of devising a procedure for attaining such a fair division was originally stated by Steinhaus in 1944: "To divide an object like a cake into two equal parts, we can adopt the old custom of letting one partner cut and the other choose. The advantage of such a procedure is obvious: neither of the partners can object to this division. The first can secure the part due him by dividing the cake into two parts that he considers to be equally valuable; the second can secure at least his due part, by choosing the more valuable part or - if he considers them equally valuable - either part. It is presumed here that the object has the property of not losing its total value by division, i.e. that the values of the parts give by addition the value of the whole, this property being admitted by both partners, even if they disagree as to the valuation of the whole object and of its parts. There exist such objects: heaps of nuts, for instance. There arises the question of how to divide fairly an object into three or more parts. (Steinhaus 1960, page 65)

16 Each player is guaranteed at least one half according to her own valuation. In fact, the first player (if she is risk-averse) will receive exactly $1 / 2$, while the second will usually get more. That means that procedure is proportional Moreover no player will envy (any of) the other(s). However "Divide and Choose" is not Pareto-optimal. Suppose two players consider dividing a cake that is half chocolate and half vanilla. Suppose one player, the divider, likes both vanilla and chocolate equally while the other player, the chooser, loves chocolate but hates vanilla. Suppose the divider cuts the cake so that each piece is half chocolate and half-vanilla. In the eyes of the divider, this represents a proportional division - each will get half, but there is another allocation that will make the chooser happier without hurting the divider, so this division is not Pareto-optimal. If the divider cut the cake half vanilla and half chocolate then the divider would be equally happy (he/she liked both) and the chooser would be much happier - she/he only wanted chocolate. 
17 A proportional fair division for any number of players called 'last-diminisher' was devised in 1944. This was attributed to Banach and Knaster by Steinhaus when he made the problem public for the first time at a meeting of the Econometric Society in Washington D.C. on 17 September 1947. At that meeting he also proposed the problem of finding the smallest number of cuts necessary for such divisions. In the first ever paper on fair division, Steinhaus (1948) reports on his own solution and a generalisation to arbitrary $n$ proposed by Banach and Knaster (Steinhaus 1948).

18 The model assumes a community or groups and its organizing and regulating rule regime.

19 Take $G$ and divide into $N$ (or $K$ part). Each member of $K_{1}$ receives allocation "a", each member of $K_{2}$ receives "b", and each member of $K_{3}$ receives "c" in the proportion: $K_{1}: K_{2}: K_{3}$.

\section{R E F E R E N C E S}

Brams, S.J, Edelman, P.H., Fishburn, P.C. (2000). Paradoxes of Fair Division, ECONOMIC RESEARCH REPORTS C.V. Starr Center for Applied Economics Department of Economics Faculty of Arts and Science, New York University.

Brams, S.J, Taylor, A.D. (1995). An Envy-free Cake Division Protocol. American Mathematical Monthly, 102(1), 9-18.

Brams, S.J, Taylor, A.D. (1996). Fair division: from cake-cutting to dispute resolution. New York: Cambridge University Press.

Buckley, W., Burns T.R., and Meeker D. (1974), Structural Resolutions of Collective Action Problems. Behavioral Science, Vol. 19, 277-297.

Burns, T.R. (1990).Models of Social and Market Exchange: Toward a Sociological Theory of Games and Social Behavior. In: C. Calhoun, M. W. Meyer, and W. R. Scott (Eds.) Structures of Power and Constraints: Papers in Honor of Peter Blau. Cambridge, Cambridge University Press.

Burns, T.R. (1994). Two Conceptions of Human Agency: Rational Choice Theory and the Social Theory of Action. In: P. Sztompka (Ed), Human Agency and the Reorientation of Social Theory. Amsterdam: Gordon and Breach.

Burns, T. R., Caldas J.C., Roszkowska E. (2005). Generalized Game Theory's Contribution to Multi-agent Modelling: Addressing Problems of Social Regulatiion, Social Order, and Effective Security. In: B. Dunin-Keplicz, A. Jankowski, A. Skowron, M. Szczuka (Eds.), Monitoring, Security and Rescue Techniques in Multiagent Systems. Springer Verlag: Berlin/London.

Burns, T.R , DeVille P. (1999). On Social Equilibria. Paper prepared for presentation at the International Economic Association's XIIth World Congress, Buenos Aires, Argentina.

Burns, T.R., Flam, H. (1987). The Shaping of Social Organization: Social Rule System Theory with Applications London: Sage Publications. 
Burns, T.R., Gomolińska A. (1998). Modeling Social Game Systems by Rule Complexes. In: L. Polkowski, A. Skowron (Eds.), Rough Sets and Current Trends in Computing. Springer-Verlag: Berlin/Heidelberg.

Burns, T. R., Gomolińska A. (2000). The Theory of Socially Embedded Games: The Mathematics of Social Relationships, Rule Complexes, and Action Modalities. Quality and Quantity: International Journal of Methodology, 34(4), 379-406.

Burns, T.R. Gomolińska A. (2001). Socio-cognitive Mechanisms of Belief Change: Application of Generalized Game Theory to Belief Revision, Social Fabrication, and Self-fulfilling Prophesy. Cognitive Systems, 2(1), 39-54.

Burns, T.R., Gomolińska A., Meeker L.D. (2001). The Theory of Socially Embedded Games: Applications and Extensions to Open and Closed Games. Quality and Quantity: International Journal of Methodology, 35(1), 1-32.

Burns, T.R, Gomolińska, A., Meeker, L. D., De Ville P. (1998). The General Theory of Games: Rule Complexes, Action Modalities, and Transformation. Uppsala Theory Circle Report, Uppsala University, Uppsala, Sweden.

Burns, T.R., Roszkowska, E. (2004). Fuzzy Games and Equilibria: The Perspective of the General Theory of Games on Nash and Normative Equilibria, In: Pal S.K, Polkowski, L., Skowron A. (Eds.) Rough-Neural Computing. Techniques for Computing with Words. Springer-Verlag, 435-470.

Burns, T.R., Roszkowska, E. (2005). Social Judgment In Multi-Agent Systems: The Perspective Of Generalized Game Theory. In: Ron Sun (Ed.), Cognition and Multi-agent Interaction. Cambridge: Cambridge University Press.

Burns, T.R., Roszkowska E., (2006a).Economic and Social Equilibria: The Perspective of GGT. Optimum - Studia Ekonomiczne, 3(31), 16-45.

Burns, T., Roszkowska, E. (2006b). Social Judgement in multi-agent systems: The Perspective of Generalized Game Theory. In: R. Sun(Ed.), Cognition and Multi-Agent Interaction. From Modeling to Social Simulation, Cambridge University Press, 409-416.

Burns, T.R., Roszkowska E. (2007). Multi-Value Decision-Making and Games: The Perspective of Generalized Game Theory on Social and Psychological Complexity, Contradiction, and Equilibrium. In: Y. Shi, (Ed.), Advances in Multiple Criteria Decision Making and Human Systems Management. Amsterdam: IOS Press.

Chapman, B., (1998a). Law Games: Defeasible Rules and Revisable Rationality. Law and Philosophy, 17, 443-480.

Chapman, B., (1998b). More Easily Done Than Said: Rules, Reasons and Rational Social Choice. Oxford Journal of Legal Studies, 18, 293-329.

Cook K.S. (1989). The Social Science Encyclopedia. London: Routledge.

Dubins L.E., Spanier E.H. (1961). How to Cut a Cake Fairly. American Mathematical Monthly, 68(1), 1-17.

Elster, J. (1992). Local Justice. New York: Russell Sage. 
Elster, J., (2006). Fairness and Norms. Social Research, 73(2), 365-376.

Granovetter, M., (1985). Economic Action and Social Structure: The Problem of Embeddedness, American Journal of Sociology, 91, 481-510.

Gomolińska, A., (1999). Rule Complexes for Representing Social Actors and Interactions. Studies in Logic, Grammar, and Rhetoric, 3(16), 95-108.

Gomolińska A., (2002). Derivability of Rules From Rule Complexes, Logic and Logical Philosophy, 10, 21-44.

Gomolińska, A., (2004). Fundamental Mathematical Notions of the Theory of Socially Embedded Games: A Granular Computing Perspective. In: S.K. Pal, L. Polkowski, A. Skowron (Eds.) Rough-Neural Computing: Techniques for Computing with Words. Springer-Verlag: Berlin/London, 411-434.

Gomolińska, A., (2005). Toward Rough Applicability of Rules. In: B. DuninKeplicz, A. Jankowski, A. Skowron, M. Szczuka (Eds.). Monitoring, Security, and Rescue Techniques in Multiagent Systems. Springer-Verlag: Berlin/London, 203-214.

Hwang, C. L., Yoon K. (1981). Multiple Attribute Decision Making: Methods and Applications. Berlin: Springer-Verlag.

Johnson, A.G. (2000). Blackwell Dictionary of Sociology, Blackwell: London.

Machado, N. (1998). Using the Bodies of the Dead: Legal, Ethical and Organizational Dimensions of Organ Transplantation. Aldershot, England: Ashgate Publishers.

Sen, A., (1998). Social Choice and Freedom. Nobel Prize Lecture, University of Uppsala, Uppsala, Sweden, December 13, 1998.

Rawls, J. (1971). A Theory of Justice. Cambridge, Mass.: Belknap Press.

Schelling, T.C. (1963). The Strategy of Conflict. Cambridge: Harvard University Press.

Simon, H. (1969). The Sciences of the Artificial. Cambridge: MIT Press.

Steinhaus, H. (1948). The Problem of Fair Division. Econometrica, 16, 101-104.

Steinhaus, H. (1960). Mathematical Snapshots. London: Oxford University Press. 